\title{
O USO DO JARDIM SENSORIAL COMO FERRAMENTA PEDAGOGICA NA INCLUSÃO DE ALUNOS COM TDAH
}

\author{
Milena Amzalak de Carvalho ${ }^{1}$
}

RESUMO: Este projeto trata da importância da inclusão de jovens com Transtorno do Déficit de Atenção e Hiperatividade nas escolas e de iniciativas que podem fazer despertar os sentidos pouco explorados em cada um dos alunos. Em um contexto de prática pedagógica cada vez mais preocupada com a acumulação de conhecimentos padronizados e quantificáveis, crianças e adolescentes que possuem esse ou algum outro tipo de transtorno do desenvolvimento acabam experimentando a exclusão diariamente em sala de aula. Considerando que essas crianças precisam de atividades que partam de direcionamentos distintos do padrão, este trabalho de pesquisa parte da hipótese de que os jardins sensoriais podem ser considerados ambientes não formais de aprendizagem que possibilitam oportunidades mais igualitárias aos jovens com TDAH, pois estimulam sua percepção por intermédio da natureza. O objetivo é promover a inclusão desses alunos em atividades em que possam interagir com os demais colegas ao mesmo tempo em que aprendem a lidar com a consciência ambiental. Espera-se que a estimulação promova nos jovens $o$ compartilhamento, a troca de saberes, visando prepará-los para o convívio em uma sociedade menos preconceituosa.

Palavras-Chave: Inclusão. Jardim sensorial. Percepção. TDAH. Aprendizagem.

ABSTRACT: This project deals with the importance of including young people with Attention Deficit Hyperactivity Disorder in schools and initiatives that can awaken the little explored senses in each of the students. In a context of pedagogical practice increasingly concerned with the accumulation of standardized and quantifiable knowledge, children and adolescents who have this or some other type of developmental disorder end up experiencing daily exclusion in the classroom. Considering that these children need activities that start from different directions from the standard, this research work starts from the hypothesis that sensory gardens can be considered non-formal learning environments that provide more equal opportunities for young people with ADHD, as they stimulate their perception by through nature. The objective is to promote the inclusion of these students in activities where they can interact with other colleagues while learning to deal with environmental awareness. It is expected that stimulation promotes the sharing and exchange of knowledge in young people, aiming to prepare them for living in a less prejudiced society.

Keywords: Inclusion. Sensory garden. Perception. TDAH. Learning.

\footnotetext{
${ }^{\mathrm{I}}$ Mestranda em Gestão. Planejamento e Ensino. Universidade Vale do Rio Verde - Unincor - Minas Gerais. E-mail: miamzalak@hotmail.com
} 


\section{INTRODUÇÃO}

Para garantir uma educação de qualidade que atinja todos os jovens estudantes seria necessário um redimensionamento das escolas voltado para a aceitação e valorização das diferenças. Esse processo de valorização se realiza através do resgate dos valores culturais que fortalecem a identidade individual e coletiva, assim como pelo respeito ao ato de aprender e de construir.

O TDAH é um transtorno do neurodesenvolvimento caracterizado por dificuldade em regular a atenção e controlar impulsos e hiperatividade, sendo considerado o mais comum em crianças e adolescentes encaminhados para serviços especializados. De acordo com a Associação Brasileira do Déficit de Atenção, ele ocorre em 3 a $5 \%$ das crianças. Esse transtorno acompanha o indivíduo até a vida adulta, porém os sintomas de inquietude tornam-se mais brandos nesta fase. A hiperatividade pode ser um problema, uma vez que pode acabar perturbando o ambiente ao redor e a criança hiperativa sendo apontada como má influência aos colegas. Acabam tornando-se a "ovelha negra" da família quando comparadas com irmãos, primos, e outras crianças da mesma faixa etária (Silva, 2003).

Segundo informações da ABDA, os portadores de TDAH têm alterações na região frontal e as suas conexões com o resto do cérebro, que é uma região das mais desenvolvidas no ser humano em comparação com outras espécies animais, sendo responsável pela inibição do comportamento e pela capacidade de prestar atenção, memória, autocontrole, organização e planejamento.

O comportamento TDAH nasce do que se chama trio de base alterada. É a partir desse trio de sintomas - formado por alterações da atenção, da impulsividade e da velocidade da atividade física e mental - que se irá desvendar todo o universo TDA, que, muitas vezes, oscila entre o universo da plenitude criativa e o da exaustão de um cérebro que não para nunca (SILVA, 2014, p. 23).

Todavia, a realidade tem se mostrado bem distinta da ideal. Estudantes com TDAH acabam não sendo incluídos de forma adequada, uma vez que a metodologia adotada pelas instituições de ensino é a mesma para todos. Nesse caso, é necessário rever os conceitos de aprendizagem em sala de aula, evitando rotular e prejudicar os alunos com necessidades educacionais especiais. 
De acordo com o proposto pela Lei de Diretrizes e Bases (LDB), a educação destina-se a todos. Pela Legislação todos os estudantes, portadores de deficiência ou transtornos devem ter atendimento educacional especializado e gratuito, preferencialmente na rede regular de ensino ( $\mathrm{LBD}, 1996$, art. $4^{\circ}$, inciso III). Contudo, uma nova Legislação intitulada Política Nacional de Educação Especial (PNEE), sugere que a educação de alunos portadores de deficiências seja realizada através de salas ou escolas especiais, contrariando o modelo que vigora no País, ou seja, nem sempre estar normatizado não significa que será praticado em sua totalidade.

\begin{abstract}
A publicação da nova "Política Nacional de Educação Especial: Equitativa, Inclusiva e com Aprendizado ao Longo da Vida" (Brasil, DECRETO № 10.502, DE 30 DE SETEMBRO DE 2020) apresenta um retrocesso para as políticas de inclusão. Apesar de parecer ampliar as opções de escolha das famílias, a política pode favorecer uma visão de segregação dos alunos com necessidades especiais, afastando-os do convívio prioritário em salas de aula do ensino regular (Kestelman, 2020).
\end{abstract}

Muitas vezes crianças com transtorno são consideradas desinteressadas, quando na verdade possuem Transtorno do Déficit de Atenção. Sabemos que algumas crianças são mais agitadas que outras. Porém as com TDAH apresentam um quadro de agitação ainda maior, associado a impulsividade e distração. Essa criança é mais intensa que as demais, ela ultrapassada o considerado padrão normal, dificultando para o professor diferenciar a criança com esse tipo de transtorno de outras consideradas típicas que também apresentam um perfil de agitação, gerando uma confusão. "Elas têm dificuldades para manter atenção em atividades muito longas, repetitivas ou que não lhes sejam interessantes. Elas são facilmente distraídas por estímulos do ambiente externo, mas também se distraem com pensamentos “internos”, isto é, vivem "voando" (ABDA, 2017).

A escola é um ambiente de troca entre os alunos e o comportamento impulsivo e distraído de algumas crianças faz com que alguns pais considerem que a inclusão possa tornar a qualidade do ensino ainda mais baixa, pois é necessário que o professor dê uma atenção diferenciada para esses alunos. Outro fator relevante, é a segregação entre os próprios alunos, seja numa atividade esportiva ou em um trabalho em grupo. O papel da escola está em acolher todos os alunos de forma igual, porém ciente de que alguns possuem necessidades especificas e necessitam de abordagens diferentes para aprender. 
As barreiras encontradas nos ambientes escolares são muitas e vão desde problemas relacionados com as estruturas físicas das instituições a falta de formação adequada aos professores. Diante desse cenário, criatividade e bom senso são as principais armas para tentar mudar o atual mapa da educação e melhorar o ensinoaprendizagem das crianças com transtorno de desenvolvimento. "A inclusão, portanto, implica mudança desse atual paradigma educacional, para que se encaixe no mapa da educação escolar que estamos retraçando" (MANTOAN, 2003, p. 12). Desse modo, para incluir é necessário romper os preconceitos, os paradigmas existentes, objetivando uma sociedade mais justa onde os professores não tenham medo da mudança, proporcionando-lhes formação adequada para que se sintam aptos a ensinar em suas salas de aula.

O papel da família é extremamente importante no desenvolvimento e na aprendizagem. Por falta de informação ou conhecimento, muitas vezes a criança é taxada como a indisciplinada e desinteressada, quando na verdade ela é vitima do TDAH. De acordo com Silva (2014) é importante buscar informações sobre o comportamento inadequado da criança antes de tirar conclusões precipitadas sobre o seu comportamento.

O Art. 205, da Constituição Federal prevê que,

$$
\begin{aligned}
& \text { A educação, direito de todos e dever do Estado e da família, será } \\
& \text { promovida e incentivada com a colaboração da sociedade, visando ao pleno } \\
& \text { desenvolvimento da pessoa, seu preparo para o exercício da cidadania e sua } \\
& \text { qualificação para o trabalho. (Brasil, 1988) }
\end{aligned}
$$

O modelo educacional que observamos em nossas escolas hoje remete uma padronização no comportamento das crianças, onde o aluno deve memorizar o mesmo conteúdo, no mesmo intervalo de tempo que seus colegas. Involuntariamente isso favorece alguns grupos de estudantes e exclui outros. Aqueles que possuem determinados tipos de transtorno do desenvolvimento que acarretam em dificuldade de aprendizado fazem parte do grupo dos excluídos. Para atender essas demandas educacionais é necessário fazer mudanças no modelo educativo atual e obter respostas mais competentes por parte dos gestores das instituições escolares, pois educar para a vida acontece a partir das relações humanas envolvendo a preocupação com a totalidade do ser. 
O projeto de Lei 708I/20Io tem por objetivo garantir que crianças e jovens com sinais de TDAH ou dislexia sejam identificados o quanto antes para que sejam encaminhados para o correto diagnóstico. Uma vez que o diagnóstico de dislexia e TDAH seja confirmado estes estudantes devem ter acesso a recursos didáticos adequados ao desenvolvimento de sua aprendizagem. Os sistemas de ensino devem garantir aos educadores formação sobre a TDAH e Dislexia bem como sobre as abordagens pedagógicas adequadas para estes casos (ABDA, 2019).

Alunos com TDAH apresentam dificuldades comportamentais em sala de aula, possuem características próprias, como inquietude e falta de atenção, que dificultam o aprendizado em sala de aula. Segundo a ABDA (2017) o diagnóstico correto e preciso do TDAH, só pode ser feito através de uma longa anamnese (entrevista) com um profissional médico especializado (psiquiatra, neurologista, neuropediatra). Nesse sentido, considerando que os estudantes precisam de atividades com direcionamentos distintos do padrão oferecido, este projeto de pesquisa se propõe a responder a seguinte pergunta: Como promover um ambiente igualitário para que os estudantes que possuem algum tipo de transtorno do desenvolvimento não sejam excluídos em sala de aula?

Este projeto parte da hipótese de que os jardins sensoriais podem ser considerados ambientes não formais de aprendizagem que possibilitam oportunidades menos excludentes aos jovens portadores de $\mathrm{TDAH}$, pois estimulam sua percepção por intermédio da curiosidade. "Precisamos continuar pesquisando para conhecer os sentidos que os sujeitos dão as suas experiências, os comportamentos que adotam em relação a si e aos outros e os sentimentos vivenciados no processo" (SAWAIA, 2006, p. I13).

Os Jardins são conhecidos desde a antiguidade e podem ser compreendidos como espaços destinados ao lazer e ao prazer podendo promover diferentes tipos de sensações através de seu contato com a natureza. "Os jardins representam uma reunião dos mais variados elementos da natureza, organizados em função do homem e podem ser consideradas verdadeiras obras de arte" (LEÃO, 2007, p.I8).

Dessa forma, ao propor a criação de um jardim sensorial espera-se abordar a criatividade, e analisar a influência que esse espaço tem sobre os estudantes. Muito mais pode ser feito para que as futuras gerações sejam beneficiadas em uma sociedade menos preconceituosa e mais acolhedora. A adoção de medidas inovadoras 
visa adaptar e modernizar os recursos existentes com a finalidade de atender e promover uma educação de qualidade e acessível para todos.

\section{OBJETIVOS}

\section{Objetivo Geral}

Considerando o contexto apresentado, o presente projeto possui como objetivo geral a implantação de jardins sensoriais como ferramenta de aprendizagem, transformando parte do ambiente escolar em uma área sensorial para práticas pedagógicas, contribuindo assim para a expansão do conhecimento e atestando a importância que os espaços não formais de ensino possuem para o desdobramento de estudantes com transtorno do desenvolvimento. Essa pesquisa além de prover mais estudos sobre a utilização dessa ferramenta pode contribuir de maneira significativa para auxiliar na inclusão de alunos com TDAH, proporcionando grandes descobertas para os estudantes, familiares e docentes.

\section{Objetivos específicos}

- Descrever como jardins sensoriais poderão favorecer a inclusão de alunos com TDAH;

- Sensibilizar e despertar atenção da escola para as dificuldades que esses estudantes enfrentam no seu cotidiano escolar.

- Discorrer sobre como constituir um jardim sensorial no ambiente de uma instituição de educação básica.

\section{JUSTIFICATIVA}

Inseridos em espaços urbanos desde o seu nascimento, o ser humano acaba por não agregar a natureza como parte de sua existência, tornando-se cada dia mais afastado do meio ambiente, uma vivência necessária e enriquecedora.

A proposta de um jardim sensorial gera a oportunidade de se desenvolver em ambientes urbanos, cercados por construções, um local de calmaria que estimule os sentidos, contribuindo também como um espaço de inclusão para pessoas com transtorno do desenvolvimento, aguçando sua curiosidade e levando-as a interagir 
com o ambiente e com outras pessoas. Tal espaço é voltado para práticas que possibilitem maior integração entre os jovens e seus professores.

Os alunos com TDAH têm direito a uma escola acessível e o gestor é responsável por construir condições para que a escola assegure este direito, quando se fala em acessibilidade, não estamos nos referindo apenas as condições físicas, mas também as condições pedagógicas. A gestão escolar inovadora, foca na eficácia da educação, sem atitudes discriminatórias. Tais medidas podem permitir que todos sejam incluídos e não apenas integrados. Para isso, o ambiente escolar deve estimular e favorecer a interação, estando fundamentado em uma proposta de trabalho que tenha como característica processos dinâmicos para a construção cognitiva, ao preparar determinado conteúdo específico, o educador deve estar atento sobre o estágio de desenvolvimento que o estudante se encontra.

“É necessário que a preparação dos professores seja simultânea à transformação da escola. Preparamos professores capacitados na observação e na experimentação. É preciso, porém, que encontrem na escola a oportunidade para observar as crianças e aplicar seus conhecimentos" (MONTESSORI, 2017, p. 33). O olhar atento dos gestores e de seus professores para uma nova possibilidade de abertura educacional pode gerar aos estudantes com transtorno do desenvolvimento uma nova perspectiva a respeito das disciplinas.

A escola ao investir em uma área sensorial está inovando e proporcionando aos seus alunos uma nova maneira de assimilar e participar das atividades. A busca por recursos que tornem a educação acessível para um maior número de alunos deve ultrapassar as paredes de concreto. "A educação não-formal capacita os indivíduos a se tornarem cidadãos do mundo, no mundo" (GOHN, 2006, p. 29). A proposta de um jardim como ferramenta pedagógica que visa trabalhar a percepção através do contato direto com a natureza, aflorando sensações nunca sentidas ou muitas das vezes retraídas.

Este projeto dialoga com a proposta da LDB de educar para vida e para o trabalho, no sentido de promover a cidadania por intermédio de uma educação igualitária, que propicie o acesso e a permanência dos estudantes a escola, respeitando sua liberdade (art. $3^{\circ}$ ). De acordo com o proposto pela LDB a educação destina-se a 
todos, porém estar normatizado não significa que está sendo praticado em toda a sua totalidade.

Todos os estudantes portadores de deficiência ou transtornos devem ter atendimento educacional especializado e gratuito, preferencialmente na rede regular de ensino (art. $4^{\circ}$, inciso III).

\section{FUNDAMENTAÇÃO TEÓRICA}

\section{O TDAH e suas implicações}

No ano de 2020 no Brasil, existiam 179.533 escolas públicas e privadas de educação básica e um total de 47,3 milhões de alunos matriculados nesse nível de ensino (BRASIL, 202I), sendo assim, aproximadamente I,8 milhões dos estudantes sofrem com esse problema.

Em virtude do TDAH o comportamento da criança e sua capacidade de aprendizagem são afetados e a escola precisa assumir um papel para organizar os

processos de ensino de maneira que favoreça a aprendizagem do aluno. É necessário que o professor identifique e conheça as dificuldades ocasionadas pelo transtorno e utilize estratégias que beneficiem este estudante na aula. Atitudes como destacar suas potencialidades e diminuir estímulos que causam distrações em sala ajudam no processo. $\mathrm{O}$ contato visual entre professor e estudante contribui na sustentação da atenção, assim como elogios e recompensas constantes se constituem em um aditivo fazendo com que se sinta parte do grupo. Estimulada e apoiada, a criança participa ativamente do tratamento, evidenciando freqüentemente criatividade e entusiasmo no manejo das dificuldades associadas ao TDAH (SILVA, 2003).

A Lei $\mathrm{n}^{\mathrm{o}}$ 12.796, que integra a LDB, considera que todas as crianças devem estar matriculadas na educação básica a partir dos quatro anos de idade e essa mesma lei se estende à educação especial, garantindo o acesso à escola de alunos com deficiência, transtornos do desenvolvimento e altas habilidades.

O TDAH é reconhecido oficialmente por vários países e pela Organização Mundial da Saúde (OMS), sendo que nos Estados Unidos os portadores são protegidos por lei quanto a receberem tratamento diferenciado na escola (ABDA, 2012). No Brasil, apesar de bem elaborada, a Política relacionada a educação especial, 
falha no sentido de ofertar atendimento a todas as crianças com transtorno de desenvolvimento. No caso dos portadores de TDAH, o cenário é ainda mais complicado por não se enquadrarem nas diretrizes que norteiam o atendimento dessas crianças, conforme explicito na Lei $\mathrm{n}^{\circ} 13.146$ de 2015 , em seu artigo $2^{\circ}$,

considera-se pessoa com deficiência aquela que tem impedimento de longo prazo de natureza física, mental, intelectual ou sensorial, o qual, em interação com uma ou mais barreiras, pode obstruir sua participação plena e efetiva na sociedade em igualdade de condições com as demais pessoas. (BRASIL, 2015).

Legalmente, em virtude de não possuírem uma Legislação especifica, esse grupo de estudantes é de certa forma prejudicado porque alunos com o TDAH tem maior probabilidade de repetência, o que pode acarretar em evasão escolar.

De acordo com Mantoan (2003, p.18) é fácil receber os "alunos que aprendem apesar da escola" e é mais fácil ainda encaminhar para as classes e escolas especiais os que têm dificuldades de aprendizagem e, sendo ou não deficientes, para os programas de reforço e aceleração. Ao analisar esse comentário percebe-se que algumas instituições ainda não estão preparadas para revitalizar a educação, pois toda criança, seja ela com TDAH ou não, possui seu próprio tempo de aprendizagem, e aqueles que possuem esse tipo de transtorno, necessitam de um tempo e de atenção maiores para assimilar o que foi ensinado.

É importante destacar que os transtornos mencionados e o TDAH não devem ser associados a baixa inteligência e que o caminho pode ser longo até que se obtenha resultados positivos. "O transtorno do déficit de atenção é um dos problemas comportamentais mais comuns da infância, responsável por dificuldades de aprendizagem, repetências e evasão escolar” (SILVA, 2014 p. 90). E para que essas crianças tenham um aproveitamento escolar satisfatório, escola e família precisam estar em sintonia. Pais, professores e orientadores educacionais devem trabalhar em conjunto, mantendo um contato direto.

Para Silva (2014) não existe uma solução simples ou mágica no trato com alunos TDA's, é algo que exige tempo, dedicação e persistência. As metodologias existentes associadas a novas podem despertar o interesse e as habilidades das crianças que possuem algum tipo de transtorno do desenvolvimento, tornando o ambiente escolar menos excludente. Para por em prática o enfoque inclusivo na 
educação e minimizar a exclusão desses jovens estudantes, é necessário destinar mais atenção a diversidade, trabalhando com currículos equilibrados, porém flexíveis, adaptados as diferentes capacidades e estilos de aprendizagem.

\section{O PAPEL DA EDUCAÇÃO NÃO FORMAL NA TRANSFORMAÇÃO DO AMBIENTE ESCOLAR}

Primeiramente é necessário compreender que o conceito de não-formal está relacionado a forma de aprendizado não convencional que é disponibilizada pela sociedade através das escolas, por intermédio dos gestores e professores. "Estimular a vida, deixando-a, porém, plenamente livre para expandir-se, eis o primeiro dever do educador" (MONTESSORI, 2017, p. 123).

Para Gohn, "as práticas da educação não-formal se desenvolvem usualmente extramuros escolares, nas organizações sociais, nos movimentos, nos programas de formação sobre direitos humanos, cidadania, práticas identitárias, lutas contra desigualdades e exclusões sociais (2009, p.31)." Criar oportunidades de ensino para que os estudantes sejam instigados a aprender a compartilhar experiências construindo pontes entre o teórico e a prática, vivenciar sensações e estimular o convivo em sociedade, são práticas que vão além da sala de aula que podem e devem ser ofertadas aos estudantes.

Mantoan (2003) argumenta que aprender implica ser capaz de expressar, dos mais variados modos, o que sabemos, representando o mundo a partir de nossas origens, de nossos valores e sentimentos. A ideia do não-formal baseia-se em uma educação pautada no compartilhamento de experiências, através de ações coletivas, visando a importância e o respeito a diversidade e a integração de todos, buscando a socialização dos indivíduos.

Quanto aos resultados que podem ser atingidos através da coletividade, Gohn (2006) destaca que o aprendizado se dá de diferentes formas, através da convivência, do respeito mútuo pela sociedade, através do reconhecimento de diferentes grupos culturais, respeitando o individualismo e o papel do outro, na construção da identidade coletiva e no delineamento de regras éticas voltadas às condutas da sociedade. 
Portanto no contexto da educação espaços não formais como jardins, museus, exposições, feiras de ciência e outros, tendem a direcionar os estudantes a participar ativamente, pois são desafiados uns pelos outros, resultando em bons resultados na interação dos estudantes com as disciplinas relacionadas. "Há na educação nãoformal uma intencionalidade na ação, no ato de participar, de aprender e de transmitir ou trocar saberes" (GOHN, 2006, p.29).

A Educação não-formal está tomando forma e espaço e se tornando um instrumento útil no diálogo dos saberes, alcançando uma dimensão de conhecimentos que vão além dos conteúdos formais. A escolarização é oferecida de forma diferenciada, com outras perspectivas, há uma preocupação de se formar indivíduos com os mais variados aspectos.

Podemos tentar descrever a educação não-formal como aquela voltada para a construção do ser humano como um cidadão do mundo. Seu objetivo não é o de substituir a educação formal e sim, complementar. "Assim, é preciso resgatar e estimular novos sentidos de percepção do ambiente, buscando a reintegração do ser humano ao meio natural a fim de que uma consciência crítica das relações sociedadenatureza possa emergir, reelaborando novas formas de convívio e de agir “(OLIVEIRA;VARGAS, 2009, p.3II).

Ao propor que a educação seja transportada para além das salas de aula que circundam as instituições de ensino, espera-se que o conhecimento e a criatividade surjam espontaneamente nos jovens, despertando a curiosidade e seus interesses para questões globais. O compartilhamento de experiências associados a vivência pessoal de cada um, visa expandir o conhecimento e o aprendizado em grupo. "Ninguém educa ninguém, ninguém se educa a si mesmo: os homens se educam em comunhão mediatizados pelo mundo" (FREIRE, 1981, p. 79).

Incluir não é apenas receber alunos com deficiência em uma sala de aula, ou em uma empresa para que a legislação seja cumprida. Segundo Mantoan (2003, p.16) a inclusão implica uma mudança de perspectiva educacional, pois não atinge apenas alunos com deficiência e os que apresentam dificuldades de aprender, mas todos os demais, para que obtenham sucesso na corrente educativa geral. É necessário adotar medidas inovadoras que possam adaptar e modernizar os recursos existentes com a 
finalidade de atender e promover uma educação de qualidade garantindo a acessibilidade de todos nas instituições de ensino.

Ao investir em uma área sensorial, o gestor escolar direciona seus alunos para um outro patamar de ensino. A inclusão veio para desafiar a educação convencional, é através do convívio que podemos construir uma sociedade que valorize e respeite as diferenças.

\section{EDUCANDO ALÉM DA SALA DE AULA, EDUCANDO PARA A VIDA}

Em virtude do excesso de atividades diárias, somos incapazes de estimular nossos órgãos dos sentidos. Fazendo somente um reconhecimento superficial daquilo que enxergamos. De acordo com Montessori,

Os sentidos são órgãos de "apreensão" das imagens do mundo exterior, necessárias ao entendimento, como a mão é o órgão de apreensão das coisas materiais necessárias ao corpo. Mas, sentidos e mãos podem afinarse além das exigências normais de suas funções, tornando-se, cada vez mais, dignos servidores do grande princípio interior de ação que os mantém a seu serviço (MONTESSORI, 2017, p.II3).

Quando fazemos referência as escolas, percebemos que não são espaços neutros, pois foram construídos de acordo com a concepção pedagógica daquela instituição, podendo estimular ou inibir as atividades desenvolvidas pelas crianças. A educação é para todos, porém não atinge por completo esse objetivo, pois cada estudante reage e interage de maneira diferente aos conceitos apresentados em sala de aula.

\footnotetext{
Geralmente, ao ensinar, falamos do objeto que nos interessa, induzindo depois o aluno, que compreendeu, a executar um trabalho relacionado com o referido objeto. Mas, não raro, o aluno, que compreendera muito bem as idéias, encontra enormes dificuldades na execução da tarefa porque faltoulhe em sua educação um fator de primeira importância: o aperfeiçoamento das sensações (Montessori, 2017, p.III).
}

A partir do momento compreendemos que a aprendizagem transcende o espaço da sala de aula, proporcionamos aos alunos interações que serão importantes para o seu desenvolvimento. Ao observar a influência do espaço externo podemos identificar potencialidades, além de apontar a maneira como determinadas experiências podem ser importantes para o crescimento individual dos estudantes.

Montessori defendia um conceito de educação para a vida baseado na liberdade, na atividade, na vitalidade e no individualismo, dessa forma os jovens são 
tratados de acordo com sua faixa etária e suas necessidades. "A criança deve ter total liberdade de escolha, pois, assim, ela não exigirá nada a não ser experiências repetidas, as quais se tornarão mais e mais percebidas pelo interesse e pela séria atenção durante a aquisição do conhecimento desejado" (Montessori, 2014, p.13).

É necessário pensar que o estudante de hoje será o arquiteto da sociedade de amanhã, e por este motivo devemos nos preocupar com sua formação, para que se tornem cidadãos com responsabilidade e iniciativa, pessoas que lutem por uma vida digna para si e para os demais. Dessa forma, precisamos pensar em uma educação que vá além dos muros escolares, para poder retornar enriquecida com novos valores, com entusiasmo e prazer de viver.

[...] a educação existe onde não há escola e por toda a parte pode haver redes e estruturas sociais de transferência de saber de uma geração a outra, onde ainda não foi sequer criado a sombra de algum modelo de ensino formal e centralizado. (BRANDÃO, 2007, p. 13).

Portanto o aprendizado não deve se restringir às salas de aula, ele deve romper e ultrapassar as barreiras impostas pelas paredes, estendendo-se a outras áreas da escola e para que isso aconteça os profissionais envolvidos precisam refletir e discutir sobre os espaços não formais e a maneira como estes podem ser utilizados como ferramenta de ensino. Eles devem ser significativos para as crianças, para que possibilite vivências e estabeleça um movimento prazeroso entre a construção do ser a construção do saber.

\section{A GESTÃO ESCOLAR E SEU PAPEL NO PROCESSO DE INCLUSÃO}

Não se deve vislumbrar a gestão escolar apenas como um apanhado de técnica e métodos, mas como à capacidade de compreender e analisar de forma crítica a realidade, os aspectos sociais e as relações humanas, questões que não podem ser explicadas por intermédio de procedimentos burocráticos, desqualificando as relações sociais presentes na escola. Neste momento, é imprescindível que a gestão escolar considere os aspectos do cotidiano escolar. "À medida que a sociedade e a escola se democratizam, inicia-se uma cobrança para que a escola, e os conteúdos por ela trabalhados, sejam mais interessantes e próximos do cotidiano e da realidade dos alunos" (ARAUJO, 2000, p.98). 
É importante considerar que o papel da escola consiste em formar cidadãos com valores e princípios éticos de valorização e respeito ao outro. A educação inclusiva precisa proporcionar no seu cotidiano um ambiente organizacional favorável que estimule o conhecimento e a cultura, concedendo aos alunos desenvolvimentos técnicos, éticos, e humanos para que se tornem emancipados e autônomos. Para que isso ocorra, a gestão escolar deve ser capaz de enfatizar os processos democráticos e participativos no cotidiano escolar, praticando uma mudança social e educacional, deixando para trás práticas individualizas.

A escola é um espaço destinado ao atendimento de todos e ao longo dos anos muito tem sido feito para que se torne também um espaço mais democrático, porém há barreira que ainda necessitam ser ultrapassadas. $O$ papel do gestor escolar e suas atribuições são elaborados para organizar a inclusão na escola de modo que a escola possa ser vista como espaço de valorização das potencialidades de seus alunos. Lidar com a diversidade existente é um trabalho que deve ser realizado em conjunto, de maneira contínua e por longo prazo, assim a parceria trará benefícios para o futuro da criança e sua convivência em sociedade.

\begin{abstract}
A escola se entupiu do formalismo da racionalidade e cindiu-se em modalidades de ensino, tipos de serviço, grades curriculares, burocracia. Uma ruptura de base em sua estrutura organizacional, como propõe a inclusão, é uma saída para que a escola possa fluir, novamente, espalhando sua ação formadora por todos os que dela participam (MANTOAN, 2003, p.12).
\end{abstract}

Trata-se de um desafio para o gestor, pois o sucesso de uma gestão inclusiva só deverá ser adquirido através de prática continuada, reflexiva e coletiva, porque a educação inclusiva é a apuração do comprometimento da educação de todos os alunos com a escola. Dessa forma fica claro que inclusão implica em mudança da perspectiva educacional, pois não lida apenas com os alunos com necessidades especiais e os que apresentam dificuldades de aprendizado, mas a todos os demais, para que obtenham sucesso na corrente educativa geral. É como uma cadeia interligada, quando acolhidos no ambiente escolar os alunos tendem a demonstram mais interesse pelas atividades e se sentem mais a vontade para falar sobre suas dúvidas e dificuldades. Uma coisa acaba levando à outra: ao se sentirem acolhidos pela escola, os estudantes se engajam o que acarreta em maior facilidade no 
aprendizado. Um ambiente acolhedor gera sensação de segurança, o que é imprescindível para identificar possíveis transtornos ou dificuldades de aprendizagem.

A inclusão escolar impõe a abertura de novas frentes de trabalho especializado, mas só conseguem percebê-las e encontrá-las os que conseguem se desvencilhar das amarras do passado e vislumbrar o futuro, como tempo de novos desafios, conquistas mudanças de toda ordem (SASSAKI, 2005, p. 28).

Portanto tanto gestor como escola devem propiciar condições para que o educando com transtorno do desenvolvimento participe das atividades escolares, e se sinta realmente incluído e aceito. Se não houver aceitação, não é possível que este processo aconteça. Escolas inclusivas consideram todas as necessidades individuais de seus alunos: pessoais, educacionais, emocionais. Ela precisa ser humanizada, centrada em valores e princípios éticos para assumir seu papel na formação de seus alunos.

Por meio da inclusão a educação se atualiza porque é necessário que as novas gerações estejam preparadas para viver em uma sociedade livre de preconceitos, respeitando o professor como orientador e profissional capacitado para exercer sua função e exigindo tanto das escolas públicas quanto das privadas a adequação de um modelo que atenda às necessidades de todos os alunos.

\section{O JARDIM SENSORIAL E SUA CONTRIBUIÇÃO PARA INCLUSÃO DE ALUNOS NAS ESCOLAS}

De acordo com os historiadores, os jardins sempre estiveram presentes como demonstração de riquezas ou de religiosidade dos povos, e desde a antiguidade o homem observa e admira as plantas, organizando cada uma delas de acordo com a disponibilidade de luz, solo e água, resultando nas mais variadas formas, tornando-se verdadeiras obras de arte. "Nos povos de cultura cristã, a origem dos jardins está associada a propósitos espirituais, sejam religiosos ou filosóficos” (DA SILVA, 20I4, p. II4).

"É um verdadeiro convite à contemplação, procurando transmitir paz e espiritualidade, além de privilegiar os aspectos filosóficos, religiosos e simbólicos" (SILVÉRIO, 20I7, p. 4). Na antiguidade os jardins costumavam ser instalados no 
interior dos palácios, ou externamente em áreas planas com raras exceções com a dos Jardins Suspensos da Babilônia, construído pelo rei Nabucodonosor para sua esposa. Uma das sete maravilhas do mundo antigo por ostentar uma audaz engenharia composta por terraços irrigados, em patamares.

Planejados para aguçar os sentidos do corpo e não apenas a visão, os jardins sensoriais estão se espalhando pelo Brasil e pelo mundo. Antigamente eram frequentemente vistos em casas, mas com passar dos anos foram sendo deixados de lado, perdendo espaço para a urbanização. “Todo jardim cultivado possui em sua gênese necessidades histórico-sociais, reveladas em seu sentido útil e na quase ausência de um valor estético" (ARAGÃO, 2008, p. 171).

Essa é a ideia que muitos possuem, porém um jardim pode ser transformado em um ambiente de aprendizado, trabalhando e desenvolvendo os sentidos sensoriais dos indivíduos a partir de elementos implantados nesses espaços, visando trabalhar sua percepção. Para se obter os resultados esperados é importante que as plantas estimulem os sentidos, se não um outro. Por isso é necessário contar com uma boa variedade de espécies, visando fazer com que o jardim atenda sua finalidade. Diferente dos jardins convencionais, um jardim sensorial pode mostrar mais do que os nossos olhos estão acostumados a ver. A associação de recursos naturais trabalhados em conjunto com atividades que possam ser realizadas nesse espaço conduz o sujeito a ter uma visão mais positiva de si e das suas capacidades, proporcionando sensação de bem estar, podendo elevar a autoestima do visitante, pois o ambiente é capaz de construir novas emoções por intermédio da estimulação dos sentidos.

Inicialmente a utilização desses jardins tinha como público-alvo pessoas com deficiência visual, tendo como seu principal propósito, proporcionar aos visitantes a possibilidade de estimular os outros sentidos, porém ao aprofundar essa pesquisa nos deparamos com a oportunidade de atingir outros grupos de pessoas, que poderiam se beneficiar através dos variados elementos que integram este ambiente. "É de suma importância o jardim sensorial visto e confirmado que só trazem benefícios a essas crianças onde podem se sentir livre e bem à vontade com a natureza uma ligação muito grande" (SILVA; ARAÚJO, 2019, p. 4). 
Para montagem de um jardim sensorial, é necessário um espaço que ofereça boa visualização e acesso aos estudantes. É importante ter critérios na escolha das plantas que vão compor o jardim, não é recomendável conter plantas com óleos que possam causar irritação na pele ou plantas que possuam partes perfurantes (espinhos) e também plantas que venham acarretar em reações alérgicas. $\mathrm{O}$ zelo existe para que nenhum frequentador venha ter eventuais problemas ao entrar em contato com alguma espécie botânica. "A escolha das espécies estudadas também precisa de critérios de segurança sendo desta maneira a possível criação com adequação e qualidade para um espaço pedagógico inclusivo" (SILVA \& LIBANO, 2014, p. o7).

$\mathrm{O}$ jardim deve atender às necessidades dos frequentadores daquele espaço, portanto é fundamental estar atento as diferentes necessidades das crianças. "A vegetação é o principal elemento de um jardim, uma vez que estrutura o espaço e propicia diferentes sensações" (BELLÉ, 2013, p. II).

Basicamente para montagem de um jardim sensorial são necessários, solo para plantio das plantas, vasos, blocos de cimento ou instalações de alvenaria, pá, carrinho de mão para transporte de algum material, o uso de garrafas pet pode reduzir os custos substituindo os vasos ou sendo utilizada como cerca. A escola pode sugerir aos estudantes recolher as garrafas e decorá-las, abordando assim a questão da Educação Ambiental, reduzindo a poluição do meio ambiente.

Para Osório (2018, p.29),

A inclusão é um movimento educacional, mas também social e político que vem defender o direito de todos os indivíduos participarem, de uma forma consciente e responsável, na sociedade de que fazem parte, e de serem aceites e respeitados naquilo que os diferencia dos outros.

É fundamental que a escola seja capaz de se adequar ao estilo de aprendizagem do aluno. O ambiente deve ser agradável e dinâmico, para que o estudante sinta prazer de estar e conviver ali. É importante que o professor saiba diferenciar incapacidade de desobediência, pois, as crianças com TDAH evidenciem dificuldades de controlar os seus impulsos.

Segundo MATTOS (20II) o professor tem que ser capaz de modificar as estratégias de ensino, adequando-as ao estilo de aprendizagem e as necessidades do aluno. A ideia do jardim sensorial é de promover através de um espaço não-formal 
recursos que desafiem os estudantes para algo novo, despertando seu interesse e sua curiosidade.

No contexto educacional é preciso considerar os aspectos cognitivos e psicossociais, sendo fundamental respeitar as etapas do desenvolvimento no qual a criança se encontra.

A educação de pessoas com transtorno do desenvolvimento é um desafio para os profissionais de diferentes áreas que com ela trabalham. No caso dos gestores escolares, estes têm como objetivo administrar recursos juntos aos professores para que possam diminuir a dificuldade dos alunos tentando ensina-los a se comunicar e a promover o seu desenvolvimento e funcionamento nas atividades propostas. É importante os profissionais criarem condições que facilitem sua autonomia e independência. $O$ estudante com transtorno do desenvolvimento tem papel determinante na sua educação, pois a sua força de vontade e determinação são aspectos fundamentais para o sucesso do seu desenvolvimento, para isso tem que ser sentir motivado e acolhido por todos a sua volta, dos familiares aos colegas de sala.

\section{CONSIDERAÇÕES FINAIS}

Os dados coletados na elaboração dessa dissertação retrataram o maior número possível de elementos, todavia, a pandemia da COVID-I9 dificultou o acesso pessoal aos profissionais envolvidos. Em virtude disso, o presente projeto sofreu adaptações durante sua elaboração e na sua execução recorremos à uma metodologia investigativa preconizando a melhoria de práticas já existentes adaptando-as as necessidades de aprendizagem dos estudantes portadores de TDAH. Esta experiência pode inspirar novas metodologias de ensino atestando a sua viabilidade por intermédio de um conjunto de ações.

Os reflexos da urbanização no cotidiano das crianças e jovens associados ao isolamento em ambientes fechados causam inúmeros prejuízos à saúde. É preciso refletir sobre o estilo de vida que adotamos nas cidades.

Partindo da idéia que os jardins sensoriais podem ser construídos em grandes ou pequenas áreas, a elaboração dessa pesquisa tornou-se ainda mais estimulante uma vez que as crianças estão cada vez mais envolvidas com jogos virtuais ou atividades 
remotas. Além de trabalhar a inclusão, os jardins são vistos como locais de convívio social e contemplação, atingindo os mais variados frequentadores.

É saudável pensar que espaços não formais de ensino, como um jardim podem contribuir com o desenvolvimento das crianças, sem causar riscos, e conscientizando os alunos, sobre a importância de respeitar a natureza e de aprender o quanto dependemos dela o nosso cotidiano. Advindo dessa perspectiva é fundamental a criação de espaços que apóiem e incentivem o movimento, a autonomia, espaços que contribuam para a diversificação e proporcionem o contato com o outro e com o meio, onde seja possível criar situações e soluções.

É importante ressaltar que um jardim sensorial, pode ser utilizado, também, por alunos que possuam outros tipos de transtorno do desenvolvimento, ficando a critério do gestor da escola e de seus professores adaptar as atividades. Uma vez inseridos no ambiente escolar, os jardins justificam-se, pois atuam como pontes interligando conhecimento e aprendizagem.

\section{REFERÊNCIAS}

ABDA. Associação Brasileira do Déficit de Atenção. O que é TDAH. Disponível em: https://tdah.org.br/sobre-tdah/o-que-e-tdah/. Acessado em: 05 MAR. 202I.

ABDA. Associação Brasileira do Déficit de Atenção. Quais as mudanças e direitos que o projeto de lei 7.08I oferecerá para as pessoas com TDAH e Dislexia no Brasil? Disponível em: https://tdah.org.br/quais-as-mudancas-e-direitos-que-o-projeto-delei-708I-oferecera-para-as-pessoas-com-tdah-e-dislexia-no-brasil/. Acessado em: 29 AGO. 2021.

A DIFERENÇA ENTRE A EDUCAÇÃO NA ESCOLA E A NÃO-FORMAL. Pedagogia ao Pé da Letra, 2013. Disponível em: <https://pedagogiaaopedaletra.com/a-diferenca-entre-a-educacao-na-escola-e-a-naoformal/>. Acessado em: 6 JUN. 2021.

ARAGÃO, Solange de. Ensaio sobre o jardim. São Paulo: Editora Global, 2008.

ARAÚJO, U. F. (2000). Escola, democracia e a construção de personalidades morais. Educação E Pesquisa, 26(2), 91-107. https://doi.org/10.1590/Si51797022000000200007.Disponível em: https://www.revistas.usp.br/ep/ 7845. Acessado em: II MAI. 202I

BRANDÃO, Carlos Rodrigues. O que é educação. São Paulo: Brasiliense, 2007. (Coleção Primeiros Passos). 
BRASIL. Constituição Da República Federativa Do Brasil. Brasília. 1998. Disponível em:http://www.planalto.gov.br/ccivil_03/Constituicao/Constituicao.htm. Acessado em: o8 Fev. 202I.

BRASIL. Presidência da República. Lei n 13146, de 6 de julho de 2015. Lei Brasileira de Inclusão da Pessoa com Deficiência. Disponível em: http://www.planalto.gov.br/ccivil_03/_ato2015-2018/2015/lei/li3146.htm. Acessado em: 31 AGO. 2021.

BELLÉ. Soeni. Apostila de Paisagismo. Instituto Federal de Educação, Ciência e Tecnologia do Rio Grande do Sul - IFRS Campus Bento Gonçalves. 2013. Disponível em:https://www.bibliotecaagptea.org.br/agricultura/paisagismo/livros/APOSTIL A\%20DE\%2oPAISAGISMO\%2oIFRS.pdf. Acessado em: 03 MAI. 2021.

FREIRE, Paulo. Pedagogia do Oprimido. ıo. ed. Rio de Janeiro: Paz e Terra, I98I.

GOHN, M.G. Educação não formal, participação da sociedade civil e estruturas colegiadas nas escolas. Ensaio: aval. pol. públ. Educ., Rio de Janeiro, v.I4, n.50, p. 2738, jan./mar. 2006. Disponível em: https://www.scielo.br/pdf/ensaio/ 0405.pdf. Acessado em: o8 Jun 2020.

GOHN, M.G. Educação não-formal, educador (a) social e projetos sociais de inclusão social. Meta: Avaliação. Rio de Janeiro, v. I, n. I, p. 28-43, jan./abr. 2009. Disponível em: file://C:/Users/Usu\%C3\%Arrio/Downloads/I-52-3-PB\%20(I).pdf. Acessado em: 26 MAR. 202I.

GOVERNO DO BRASIL. Educação Básica teve 47,3 milhões de matrículas em 2020. Disponível em: https://www.gov.br/pt-br/noticias/educacao-epesquisa/2021/oI/educacao-basica-teve-47-3-milhoes-de-matriculas-em-2020.

Acessado em: I6 AGO. 2021.

KESTELMAN, Iane. Nova Política Nacional de Educação Especial Ignora TDAH e Dislexia. Disponível em: https://tdah.org.br/politica-de-educacao-especial-ignoratdah-e-dislexia/. Acessado em: 24 OUT. 202I

LAKATOS, E. M.; MARCONI, M. A. Metodologia do trabalho científico. 4 ed. São Paulo: Atlas, i992.

LDB - Lei de Diretrizes e Bases da Educação (Lei no 9.394). Brasília, 1996. Disponível em:http://portal.mec.gov.br/index.php?option=com_content $\&$ view $=$ article $\&$ id $=1290$ 7:legislacoes\&catid=70:legislacoes. Acessado em: i9 AGO. 2020.

LEÃO, José Flávio Machado César. Identificação, seleção e caracterização de espécies vegetais destinadas à instalação de jardins sensoriais táteis para deficientes visuais, em Piracicaba (SP), Brasil. 2007. Tese (Doutorado em Fitotecnia) - Escola 
Superior de Agricultura Luiz de Queiroz, Universidade de São Paulo, Piracicaba, 2007. doi:10.11606/T.II.2007.tde-I8102007-I04447. Acessado em: 28 MAI. 2020.

MONTESSORI, Maria. A descoberta da criança: pedagogia científica / tradução de Pe. Aury Maria Azélio Brunetti - Campinas, SP: Kírion, 2017. Disponível em: file:///C:/Users/Usu\%C3\%Arrio/Documents/Disserta\% $\mathrm{C}_{3} \% \mathrm{~A}_{7 \%}{ }_{3} \mathrm{C}_{3} \% \mathrm{~A}_{3} 0 /$ Maria \%20Montessori\%20\%20A\%2odescoberta\%20da\%20crian\%C3\%A 7a\%20\%E2\%80\%93\% 2oPedagogia\%20Cient\%C3\%ADfica\%20(2.ed)-Vide\%2oEditorial.pdf. Acessado em: 25 ABR 2021.

MONTESSORI, Maria. Para educar o potencial humano (livro eletrônico] tradução: Mirian Santini; consultoria e revisão da tradução: Sonia Maria Alvarenga Braga. Campinas, SP: Papirus. 2014.3.039 Kb: PDF. Disponível em: file:///C:/Users/Usu\%C3\%Arrio/Documents/Disserta\%C3\%A 7\%C3\%A30/(Mont essori)\%20M aria\%20Montessori\%20\%20Para\%20Educar\%200\%20Potencial\%20Huma no-Papirus\%2oEditora\%2o(2014).pdf. Acessado em: 26 ABR. 2021.

MANTOAN. Maria Teresa Eglér. Inclusão Escolar: O que é? Por quê? Como fazer? Ed. I⿳a . São Paulo: Moderna, 2003. (Coleção cotidiano escolar).

MATTOS, Paulo - No Mundo da Lua: Perguntas e Respostas sobre Transtorno do Déficit de Atenção com Hiperatividade em Crianças, Adolescentes e Adultos - ı. Ed. ABDA-Associação Brasileira do Déficit de Atenção: 20II.

OLIVEIRA, T. L. de F., \& Vargas, I. A. de. (2012). Vivências Integradas à Natureza: Por uma Educação Ambiental que estimule os sentidos. REMEA - Revista Eletrônica Do Mestrado Em Educação Ambiental, 22. Disponível em: file:///E:/Mestrado/Disserta\%C3\%A 7\%C3\%A30/Vivencias\%2ointegradas\%20a\%20 natureza.pdf. Acessado em: 24 MAR. 2021.

OSÓRIO, M.G.W. O jardim sensorial como instrumento para a educação ambiental, inclusão e formação humana. Trabalho de Conclusão de Curso apresentado ao Curso de Ciências Biológicas da Universidade Federal de Santa Catarina como requisito para a obtenção do título de Bacharel em Ciências Biológicas. 2018. Disponível em: https://repositorio.ufsc.br/bitstream/handle/123456789/192871/TCC\%20\%20Maria\% 20Gabriela\%2oW..pdf? sequence $=\mathrm{I} \&$ isAllowed $=y$. Acessado em: 05 JUL. 2020 .

SASSAKI, R. K. Inclusão: o paradigma do século 2r. Inclusão: Revista da Educação Especial, Brasília, MEC/Secretaria de Educação Especial, ano I, n. I, p.ı-23, out. 2005 .

SAWAIA, Bader Burihan. As artimanhas da exclusão. Análise psicossocial da exclusão e da desigualdade social. 6- Ed. Petrópolis: Editora Vozes. 2006. P. II3

SOCIEDADE ANTROPOSOFICA NO BRASIL (SAB).Princípios da Pedagogia Waldorf. Disponível em: http://www.sab.org.br/portal/pedagogiawaldorf/369principios-pedagogia-waldorf. Acessado em: o6 JUN. 202I. 
DA SILVA. Joelmir Marques. Um passeio pela história dos jardins e um olhar para a criação dos primeiros jardins modernos no Brasil. Revista Espaço Acadêmico - № 156 - Maio 2104. Mensal. Ano XIII. Disponível em: http://jardimbotanico.recife.pe.gov.br/sites/default/files/midia/arquivos/paginabasica/20.pdf. Acessado em: 29 ABR. 2021.

SILVA. Ana Beatriz Barbosa. Mentes Inquietas: TDAH: desatenção, hiperatividade e impulsividade. Rio de Janeiro: 4르 Ed. - São Paulo: Globo, 2014. 304 pp.

SILVA, larissa roberta gritten da; ARAÚJO, Arthur Silva. AUTISMO: ESTUDO DE CASO EM JARDIM SENSORIAL PARA CRIANÇA NO ESPECTRO AUTISTA. In: XV ENFOC - Encontro de Iniciação Científica, XIV Fórum Científico, VI Seminário PIBID - Programa Institucional de Bolsa de Iniciação à Docência e I Seminário do Programa de Residência Pedagógica. Anais. Curitiba(PR) UNINTER, 2019. Disponível em: <https//www.even3.com.br/anais/ER2o19/194472AUTISMO--ESTUDO-DE-CASO-EM-JARDIM-SENSORIAL-PARACRIANCA-NO-ESPECTRO-AUTISTA>. Acessado em: o5 JUL. 2020.

SILVA, Moisés de Oliveira Cintra; LIBANO, Andréa. Botânica para os sentidos: preposição de plantas para elaboração de um jardim sensorial. Brasília, DF. 2014.

SILVERIO, P.H.B. Jardim sensorial da UFJF, um espaço de terapia e conscientização. Dissertação apresentada ao programa de pós-graduação da Universidade Federal de Juíz de Fora - MG. 2017. Disponível em: https://www.ufjf.br/ecologia/files/2018/o8/dissertacao_2017_paulo_silverio.pdf. Acessado em: 05 JUL. 2020. 